\title{
PERANCANGAN SISTEM INFORMASI PENJUALAN DAUR ULANG BOTOL BEKAS (PET) BERBASIS WEB
}

\author{
Aad Aediyansyah \\ Program Studi Manajemen Informatika \\ AMIK BSI Jakarta \\ aadafz.crb@gmail.com
}

\begin{abstract}
Plastic bottle recycling is the use of recycling unused bottles into various kinds of goods or products for our daily needs, this product is also not only useful for decoration but also can be used as a daily necessity product. Currently there are not many sites selling used plastic bottles online. In this case the author tries to analyze the information system for recycling sales of web-based plastic bottles. Some sales data collection processes sometimes occur in recording errors, inaccurate sales reports are made and delays in searching for the required data. In addition, at the moment there are still many factories that are currently poorly managed and conventional, and the data collection method for the sale of their goods is not well managed. This sales information system development model uses the Waterfall Model, because it is easy in the process of applying information systems development. The purpose of this study is to provide convenience to consumers in online purchases, without having to come directly to the factory. Make it easy for consumers to get information about products in detail through the website.
\end{abstract}

Keywords: Sales Information System, Waterfall Model, Sales of Used Bottles

\begin{abstract}
Abstrak
Daur ulang botol plastik merupakan pemanfaatan daur ulang botol-botol yang sudah tidak terpakai menjadi berbagai macam bahan barang ataupun produk kebutuhan kita sehari-hari, produk ini juga bukan hanya bermanfaat hiasan semata tetapi juga dapat dimanfaatkan sebagai suatu prodak kebutuhan sehari hari. Saat ini banyak belum banyak situs penjualan botol plastik bekas secara online. Dalam hal ini penulis mencoba menganalisa sistem informasi penjualan daur ulang botol plastik berbasis web. Beberapa proses pendataan penjualan kadang terjadi kesalahan dalam pencatatan, kurang akuratnya laporan penjualan yang dibuat dan keterlambatan dalam pencarian data-data yang diperlukan. Selain Pada saat ini masih banyak pabrik-pabrik yang cara pendataan penjualanan barangnya saat ini masih kurang dikelola dengan baik dan masih konvensional, dan tidak terdata dengan baik. Model pengembangan system informasi penjualan ini menggunakan Model Waterfall, dikarena mudah dalam proses penerapan pengembagan system informasi. Tujuan penelitian ini untuk memberikan kemudahan pada konsumen dalam pembelian secara online, tanpa harus datang langsung ke Pabrik. Memudahkan konsumen untuk mendapatkan informasi tentang produk secara detail melalui website.
\end{abstract}

Kata Kunci: Sistem Informasi Penjualan, Model Waterfall, Penjualan Botol-Botol Bekas

\section{PENDAHULUAN}

Dalam kehidupan sehari-hari kita pasti menggunakan berbagai macam peralatan yang menggunakan bahan dasar botol plastik untuk keperluan ataupun untuk hiasan rumah sehari hari. Daur ulang botol plastik merupakan pemanfaatan daur ulang botol-botol yang sudah tidak terpakai menjadi berbagai macam bahan barang (Sari, Sunarko, \& Hardati, 2016) ataupun produk kebutuhan kita sehari-hari, produk ini juga bukan hanya bermanfaat hiasan semata tetapi juga dapat dimanfaatkan sebagai suatu prodak kebutuhan sehari hari. Saat ini banyak belum banyak situs penjualan botol plastik bekas secara online. Dalam hal ini penulis mencoba menganalisa sistem informasi penjualan daur ulang botol plastik berbasis web. Beberapa proses pendataan penjualan kadang terjadi kesalahan dalam pencatatan (Christian \& Ariani, 2018), kurang akuratnya laporan penjualan yang dibuat (Suci, Zuraidah, \& Wajhillah, 2016) dan keterlambatan dalam pencarian data-data yang diperlukan (Sintawati \& Sari, 2017). 
Selain Pada saat ini masih banyak pabrik-pabrik yang cara pendataan penjualanan barangnya saat ini masih kurang dikelola dengan baik dan masih konvensional (Frieyadie, 2014), (Rachmawati, Septiana, \& Yulianti, 2016) dan tidak terdata dengan baik. Dengan adanya permasalahan tersebut maka harus ada suatu perkembangan dalam penjualan daur ulang botol-botol agar mudah di jangkau oleh pembeli, sebab itu penulis mencoba untuk membuat sebuah media pemasaran botol-botol daur ulang dengan membangun situs penjualan secara online atau lebih sering disebut dengan e-commerce dengan menggunakan fasilitas internet, agar pembeli tidak kesulitan untuk mendapatkan produk yang diinginkan, tanpa perlu datang langsung ke pabrik untuk membeli prodak yang akan di beli tersebut.

Model pengembangan system informasi penjualan ini menggunakan Model Waterfall, dikarena mudah dalam proses penerapan pengembagan system informasi. Tujuan penelitian ini untuk memberikan kemudahan pada konsumen dalam pembelian secara online, tanpa harus datang langsung ke Pabrik. Memudahkan konsumen untuk mendapatkan informasi tentang produk secara detail melalui website.

\section{METODOLOGI PENELITIAN}

\section{Teknik Pengumpulan Data}

Metode pengumpulan data yang digunakan dengan beberapa metode, meliputi :

1. Metode Observasi

Dalam pengumpulan data ini penulis mengadakan pengamatan pada situs website yang menjual daur ulang botol-botol bekas dengan melihat jalannya proses penjualan produk tersebut.

2. Metode Studi Pustaka

Pengumpulan data dan informasi yang diperlukan dengan cara mempelajari buku-buku yang berkaitan dengan permasalahan yang dibahas, sehingga didapatkan dasar ilmiah yang kuat.

\section{Model Pengembangan Perangkat Lunak}

Rekayasa perangkat lunak ini juga mengumpulkan kebutuhan pada tingkat bisnis strategis, yaitu:

1. Analisa Kebutuhan Software

Tahap ini sangat menekan pada masalah pengumpulan kebutuhan penggunaan sistem dengan menentukan konsep system, fungsional sistem yang menghubungkan dengan lingkungan sekitar yang menghasilkan spesifikasi sistem.

2. Desain

Merupakan tahapan proses multi langkah yang focus pada desain pembuatan program perangkat lunak struktur data, arsitektur data perangkat lunak dan representasi antar muka.

\section{Pengkodean}

Pembuatan kode program pada tahap ini desain harus di implementasikan ke dalam program perangkat lunak. hasil dari tahap ini adalah program computer yang sesuai dengan desain yang telah di buat.

4. Pengujian

Merupakan tahapan yang focus pada secara logika dan fungsional dan memastikan semua sudah di uji. Metode yang digunakan untuk pengujian yaitu Black Box Testing.

\section{Implementasi}

Pada tahap ini perancangan perangkat lunak direalisasikan sebagai serangkaian program atau unit program. Kemudian pengujian unit melibatkan fertivikasi bahwa setiap unit program telah memenuhi spesifikasinya. Tiap aktivitas yang digunakan untuk dapat melakukan evaluasi suatu atribut atau kemampuan dari program atau sistem dan menentukan apakah memenuhi kebutuhan atau hasil yang diharapkan

\section{HASIL DAN PEMBAHASAN}

\section{Analisa Kebutuhan Software}

Analisa kebutuhan untuk website Penjualan daur ulang botol bekas yang diusulkan dengan beberapa prosedur diantaranya

\section{A. Kebutuhan Pengunjung}

A.1. Pengunjung dapat melihat Halaman Utama

A.2. Pengunjung dapat melihat Profil

A.3. Pengunjung dapat melihat Barang yang dijual

A.4. Pengunjung dapat melihat Panduan

Berbelanja

A.5. Pengunjung dapat melihat Testimoni Pembeli

A.6. Pengunjung dapat melakukan Daftar Akun Baru

\section{B. Kebutuhan Pembeli}

B.1. Pembeli dapat melakukan Login

B.2. Pembeli dapat mengecek Lupa Password

B.3. Pembeli dapat Memasukan ke Keranjang Belanja

B.4. Pembeli dapat melihat History transaksi

B.5. Pembeli dapat menginput Testimoni 
B.6. Pembeli dapat melakukan Konfirmasi Pembayaran

C. Kebutuhan Penjualan

C.1. Penjualan dapat mengganti Password

C.2. Penjualan dapat mengelola Data Kota

C.3. Penjualan dapat mengelola Data Barang

C.4. Penjualan dapat mengelola Data Pembeli

C.5. Penjualan dapat mengelola Pemesanan Barang

C.6. Penjualan dapat mengelola Konfirmasi

Pembayaran

C.7. Penjualan dapat mengelola Laporan Pemesanan

C.8. Penjualan dapat mengelola Laporan

Pembayaran

\section{Perancangan (Desain)}

Analisa kebutuhan untuk website Penjualan daur ulang botol bekas yang diusulkan dengan beberapa prosedur diantaranya

\section{A. Desain Sistem Informasi}

\section{Desain Fungsional Sistem dengan Usecase Diagram}

a. Usecase Diagram Fungsional Kebutuhan Pengunjung

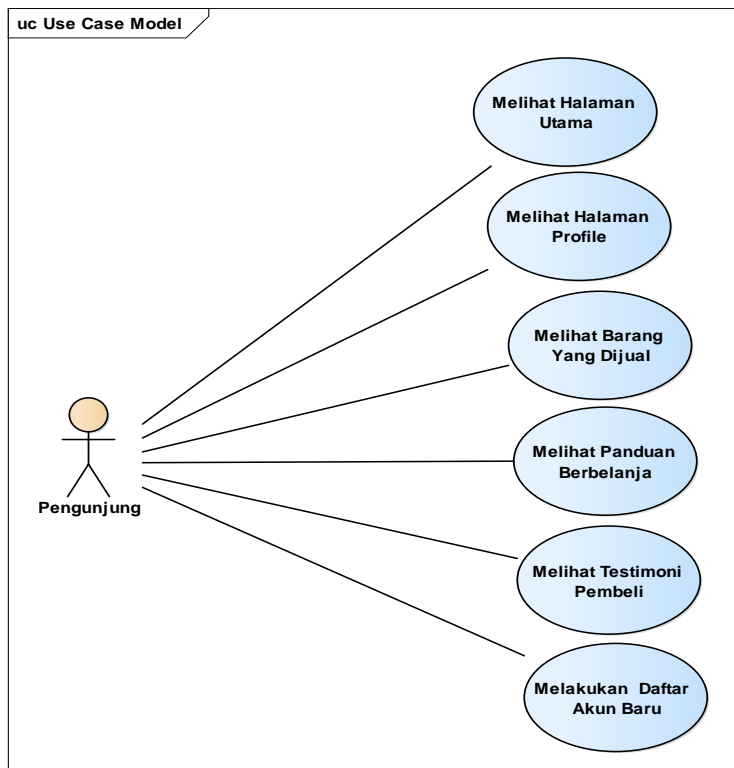

Sumber: (Aediyansyah, 2016)

Gambar 1. Rancangan Fungsional Kebutuhan Pengunjung

b. Usecase Diagram Fungsional Kebutuhan Pembeli.

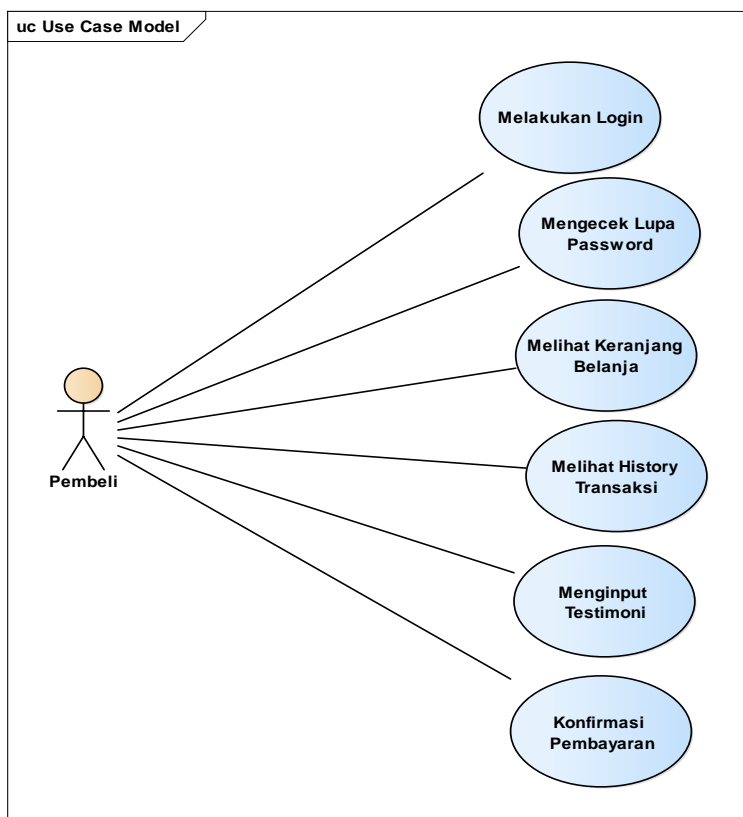

Sumber: (Aediyansyah, 2016)

Gambar 2. Rancangan Fungsional Kebutuhan Pembeli

c. Usecase Diagram Fungsional Kebutuhan Penjual

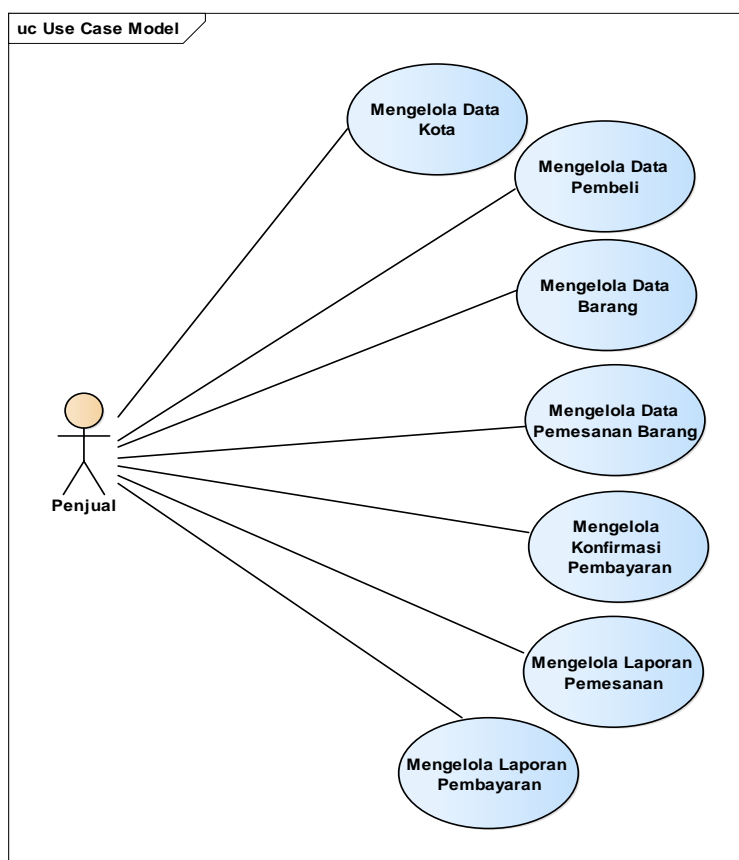

Sumber: (Aediyansyah, 2016)

Gambar 1. Rancangan Fungsional Kebutuhan Penjual

\section{B. Desain User Interface}

1. Rancangan User Interface Halaman Awal Web. Halaman pelanggan adalah halaman yang dapat diakses oleh user yang telah melakukan 
registrasi. Melalui halaman pembeli ini, pengunjung dapat melakukan pembelian produk.

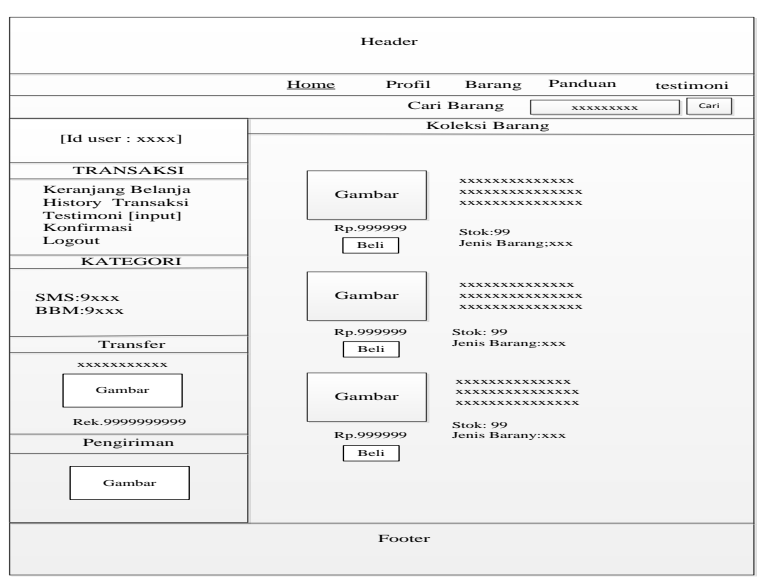

Sumber: (Aediyansyah, 2016)

Gambar 4. Rancangan Halaman Awal

2. Rancangan User Interface Keranjang Belanja Halaman keranjang belanja merupakan halaman dimana digunakan pembeli untuk menampung data-data barang yang akan dipesan.

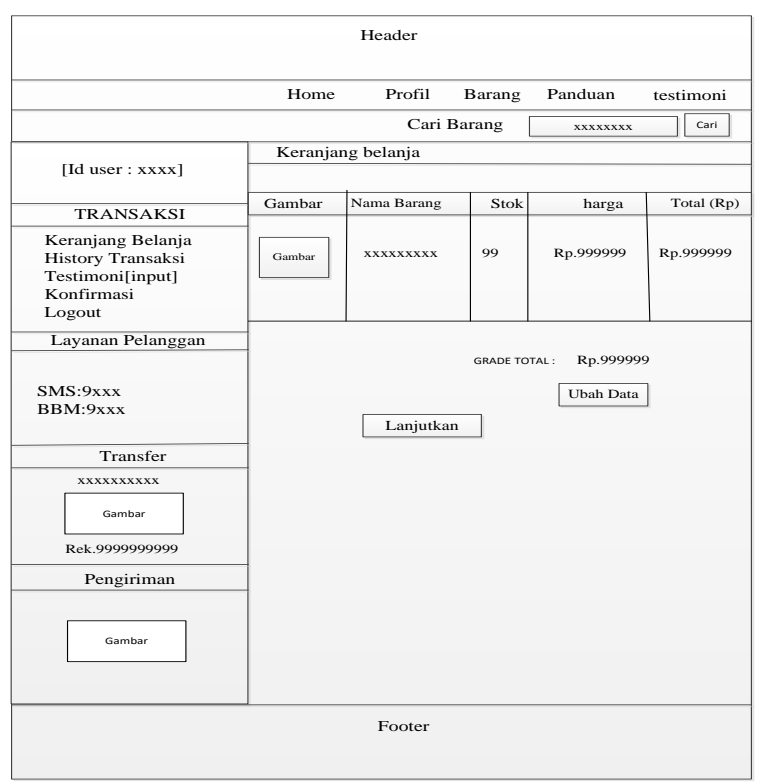

Sumber: (Aediyansyah, 2016)

Gambar 5. Rancangan Halaman Keranjang Belanja

3. Rancangan User Interface Mengelola Data Barang.

Halaman mengelola data barang merupakan halaman dimana digunakan penjual untuk mengelola meta data item barang yang dijual.

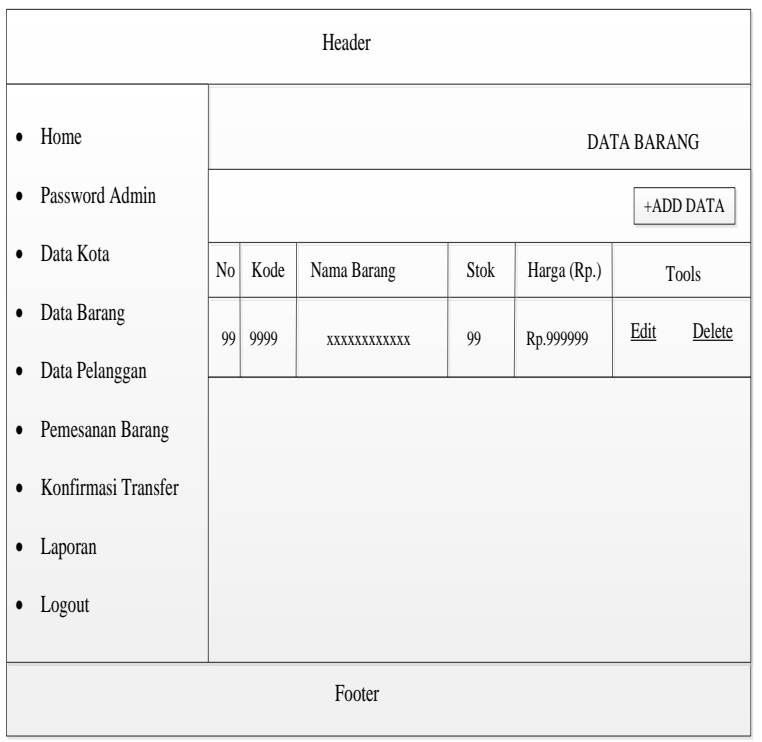

Sumber: (Aediyansyah, 2016)

Gambar 6. Rancangan Halaman Mengelola Data Barang

\section{Desain Basis Data}

1. Rancangan Entity Relationship Diagram

Berikut rancangan basis data secara abstrak dengan menggunakan perangkat rancangan basis data Entity Relationship Diagram (ERD).

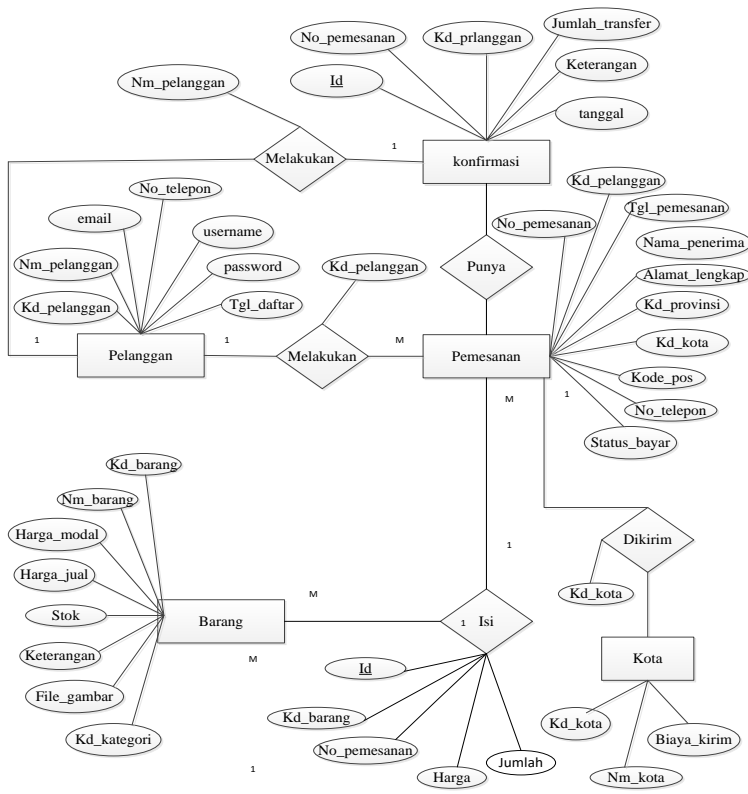

Sumber: (Aediyansyah, 2016)

Gambar 8. Rancangan ERD Sistem Daur Ulang Botol

2. Rancangan Logical Record Struktur

Berikut rancangan LRS yang merupakan hasil dari pemodelan Entity Relationship (ER) berserta atributnya sehingga bisa terlihat hubunganhubungan antar entitas. 


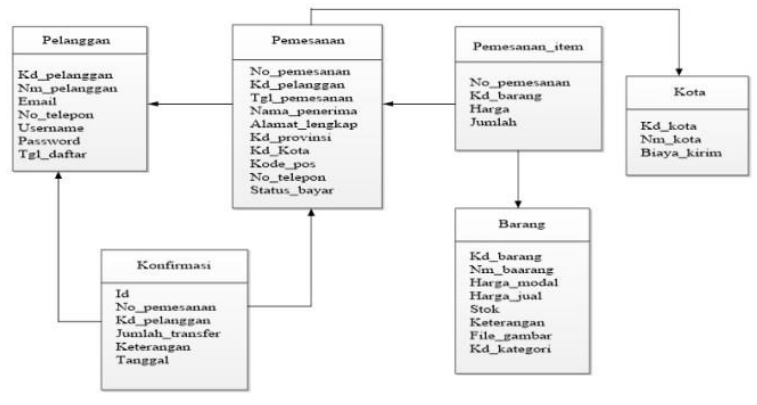

Sumber: (Aediyansyah, 2016)

Gambar 8. Rancangan LRS Sistem Daur Ulang Botol

\section{Pengkodean (Code)}

Pengkodean (Code) merupakan tahap dimana dilakukan setelah melakukan kegiatan desain atau perancangan. Adapun pengkodean tidak ditampilkan dikarenakan yang akan ditampilkan adalah source code program dimana sangat banyak sekali. Untuk itu penulis hanya menyebutkan Bahasa script yang digunakan untuk membangun system informasi ini. Adapun Bahasa script yang digunakan PHP, HTML, CSS, dan beberapa bahasa script pendukung.

\section{Pengujian (Testing)}

Pengujian pada pembuatan system informasi penjualan daur ulang botol bekas, dengan menggunakan metode black box testing. Berikut contoh pengujian pada login pembeli.

Tabel 1. Pengujian Login

\begin{tabular}{|c|c|c|c|c|c|}
\hline $\begin{array}{l}\mathbf{N} \\
\mathbf{0}\end{array}$ & $\begin{array}{c}\text { Scenario } \\
\text { pengujian }\end{array}$ & $\begin{array}{l}\text { Test } \\
\text { case }\end{array}$ & $\begin{array}{c}\text { Hasil yang } \\
\text { diharapka } \\
\text { n }\end{array}$ & $\begin{array}{c}\text { Hasil } \\
\text { penguji } \\
\text { an }\end{array}$ & $\begin{array}{l}\text { Kesimpul } \\
\text { an }\end{array}$ \\
\hline 1. & $\begin{array}{l}\text { Mengosongk } \\
\text { an isian } \\
\text { username } \\
\text { dan } \\
\text { password } \\
\text { lalu } \\
\text { langsung } \\
\text { mengklik } \\
\text { tombol login }\end{array}$ & $\begin{array}{l}\text { Usernam } \\
e: \\
\text { (kosong) } \\
\text { password } \\
: \\
\text { (kosong) }\end{array}$ & $\begin{array}{l}\text { Login anda } \\
\text { salah } \\
\text { sistem } \\
\text { menampilk } \\
\text { an } \\
\text { "data } \\
\text { username } \\
\text { dan } \\
\text { password } \\
\text { yang anda } \\
\text { masukan } \\
\text { belum } \\
\text { benar". }\end{array}$ & $\begin{array}{l}\text { Sesuai } \\
\text { harapan }\end{array}$ & Valid \\
\hline 2. & $\begin{array}{l}\text { Mengisi } \\
\text { username } \\
\text { dan } \\
\text { mengosongk } \\
\text { an password } \\
\text { kemudian } \\
\text { klik tombol } \\
\text { login }\end{array}$ & $\begin{array}{l}\text { Usernam } \\
e: \\
\text { bambang } \\
\text { password } \\
: \\
\text { (kosong) }\end{array}$ & $\begin{array}{l}\text { Login anda } \\
\text { salah } \\
\text { sistem } \\
\text { menampilk } \\
\text { an } \\
\text { menampilk } \\
\text { an "data } \\
\text { password } \\
\text { kosong, } \\
\text { silahkan isi } \\
\text { dengan } \\
\text { benar". }\end{array}$ & $\begin{array}{l}\text { Sesuai } \\
\text { harapan }\end{array}$ & Valid \\
\hline 3. & Mengisi & Usernam & $\operatorname{login}$ & Sesuai & Valid \\
\hline
\end{tabular}

\begin{tabular}{|c|c|c|}
\hline $\begin{array}{l}\text { username } \\
\text { dan } \\
\text { password } \\
\text { dengan data } \\
\text { yang benar } \\
\text { kemudian } \\
\text { klik tombol } \\
\text { login } \\
\end{array}$ & $\begin{array}{l}e: \\
\text { bambang } \\
\text { Passwor } \\
d: \\
\text { bambang }\end{array}$ & $\begin{array}{l}\text { berhasil harapan } \\
\text { menampilk } \\
\text { an pesan } \\
\text { "selamat } \\
\text { datang di } \\
\text { website } \\
\text { kami" }\end{array}$ \\
\hline
\end{tabular}

\section{KESIMPULAN}

Sistem informasi yang dibangun saat ini menggunakan model Waterfall, dikarena untuk memudahkan membangun sistem informasi pengelolaan pendataan botol-botol bekas untuk daur ulang. Memberikan kemudahan informasi pada konsumen dalam pembelian secara online, tanpa harus datang langsung ke Pabrik. Sistem dapat menyediakan informasi sesuai yang dibutuhkan pengelola daur ulang botol bekas, laporan transaksi pemesanan botol daur ulang, dan laporan penjualan. Dengan adanya fasilitas tersebut maka pengelola akan lebih mudah, cepat dan akurat dalam membuat laporan karena pengolahan datanya dilakukan oleh sistem.

\section{REFERENSI}

Aediyansyah, A. (2016). Laporan Akhir Penelitian "Perancangan Sistem Informasi Penjualan Daur Ulang Botol Bekas (Pet) Berbasis Web." Jakarta.

Christian, A., \& Ariani, F. (2018). RANCANG BANGUN SISTEM INFORMASI PEMINJAMAN PERANGKAT DEMO VIDEO CONFERENCE BERBASIS WEB DENGAN METODE WATERFALL. Jurnal Pilar Nusa Mandiri, 14(1), 131-136. Retrieved from http://ejournal.nusamandiri.ac.id/ejurnal/i ndex.php/pilar/article/view/802

Frieyadie, F. (2014). PENGGUNAAN MODEL RAD UNTUK PEMBANGUNAN SISTEM INFORMASI PENJUALAN TIKET BUS ONLINE. Jurnal Pilar Nusa Mandiri, 10(2), 204-208. Retrieved from http://ejournal.nusamandiri.ac.id/ejurnal/i ndex.php/pilar/article/view/359

Rachmawati, Y., Septiana, L., \& Yulianti, S. D. (2016). SISTEM INFORMASI PENJUALAN ALAT TULIS KANTOR BERBASIS WEB PADA CV. SUMBER REZEKI JAKARTA. In Seminar Nasional Ilmu Pengetahuan dan Teknologi Komputer (p. INF283-INF.288). Jakarta: PPPM STMIK Nusa Mandiri Jakarta. 
Retrieved

from https://konferensi.nusamandiri.ac.id/prosid ing/index.php/sniptek/article/view/231

Sari, I. Y., Sunarko, S., \& Hardati, P. (2016). TINGKAT PENGETAHUAN WARGA KAMPUS DI FAKULTAS ILMU SOSIAL UNIVERSITAS NEGERI SEMARANG TENTANG PENGELOLAAN SAMPAH. Edu Geography, 4(3), 50-56. Retrieved from https://journal.unnes.ac.id/sju/index.php/e dugeo/article/view/13815

Sintawati, I. D., \& Sari, A. M. (2017). PERANCANGAN SISTEM INFORMASI PENJUALAN PERLENGKAPAN TIDUR BERBASIS WEB STUDI KASUS TOKO BATIK
GALINAH JAKARTA. Paradigma - Jurnal Komputer Dan Informatika, 19(2), 127-130. https://doi.org/10.31294/P.V19I2.2331

Suci, F., Zuraidah, E., \& Wajhillah, R. (2016). PERANCANGAN SISTEM INFORMASI PERSEDIAAN BARANG PADA PT. CIPTA NIAGA SEMESTA SUKABUMI BERBASIS INTRANET. Seminar Nasional Ilmu Pengetahuan Dan Teknologi Komputer, 135INF.142. Retrieved from http://konferensi.nusamandiri.ac.id/prosidi ng/index.php/sniptek/article/view/253 